\title{
Nutritional status and metabolic risk in HIV-infected university students: challenges in their monitoring and management
}

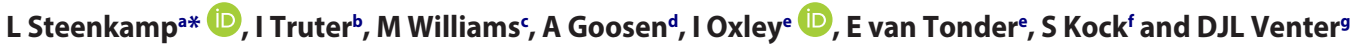 \\ ${ }^{a}$ HIV\&AIDS Research Unit, Nelson Mandela Metropolitan University, Port Elizabeth, South Africa \\ ${ }^{b}$ Department of Pharmacy, Drug Utilization Research Unit (DURU), Nelson Mandela Metropolitan University, Port Elizabeth, South Africa \\ 'Department of Nursing, Nelson Mandela Metropolitan University, Port Elizabeth, South Africa \\ ${ }^{d}$ Campus Health Service, Nelson Mandela Metropolitan University, Port Elizabeth, South Africa \\ ${ }^{e}$ Department of Dietetics, Nelson Mandela Metropolitan University, Port Elizabeth, South Africa \\ ${ }^{f}$ Department of Human Movement Science, Nelson Mandela Metropolitan University, Port Elizabeth, South Africa \\ 'Unit for Statistical Consultation, Nelson Mandela Metropolitan University, Port Elizabeth, South Africa \\ *Corresponding author, email: liana.steenkamp@nmmu.ac.za
}

\begin{abstract}
Objective: This study aims to describe challenges in the management of HIV-infected university students focusing on their nutritional status and metabolic risk.

Methods: A cross-sectional, descriptive study design was used to assess the anthropometry, food intake and clinical status of a cohort of known HIV-infected registered students at a South African university.

Results: Participants $(n=63)$ had a mean CD4 cell count of 411 (SD =219.9) cells $/ \mathrm{mm}^{3}$, a mean body mass index (BMI) of 28.05 $(\mathrm{SD}=7.9) \mathrm{kg} / \mathrm{m}^{2}$ and only half of the participants $(n=31)$ were on antiretroviral therapy (ART). A higher BMI $\left(>25 \mathrm{~kg} / \mathrm{m}^{2}\right)$ was significantly $(p<0.05 ; \mathrm{V}=0.32)$ associated with higher CD4 cell counts of $>350$ cells $/ \mathrm{mm}^{3}$. Some $40 \%(n=25)$ of students were at risk for metabolic complications based on their waist circumference and $11 \%(n=7)$ had clinical signs of lipodystrophy. The 'obese' group consumed a mean energy intake of $24 \mathrm{kcal} / \mathrm{kg}$ bodyweight which was lower than the 'overweight' and normal weight groups.

Conclusions: In total $51 \%$ of HIV-positive students in the sample presented with signs of metabolic complications. Side effects of ART can be prevented and/or treated by regular physical activity, adequate nutritional intake, monitoring of side effects and BMI, combined with optimal care and support.
\end{abstract}

Keywords: challenges, HIV, management, metabolic risk, nutrition, students

\section{Introduction}

The human immunodeficiency virus (HIV) prevalence in South Africa was reported to be $12.2 \%$ in 2012 with the highest HIV incidence in females between the ages of 20 and 34 years. ${ }^{1}$ The HIV treatment programme in South Africa has been up-scaled in recent years to cover more than $80 \%$ of those needing treatment. ${ }^{2}$ Associated with this increase in access to antiretroviral therapy (ART), the life expectancy among HIV-infected individuals increased dramatically, ${ }^{3}$ as in other developing countries. ${ }^{4}$ Despite these advances, the increased infection rate ${ }^{1}$ remains a public health concern, which means that healthcare professionals will have to continue to manage HIV-infected patients for decades to come.

HIV risk behaviour among South African youth remains unacceptably high with more than $10 \%$ of respondents reporting multiple sexual partners. ${ }^{1}$ The HIV prevalence among university students in South Africa was recently reported to be $3.4 \%{ }^{4}$ and campus health services, as well as clinicians practising near higher institution campuses, may be faced with increasing numbers of HIV-infected students. At the South African university where this study was conducted, students who test positive for HIV are entered into an HIV wellness programme, which allow for monthly visits for a full health assessment. Students eligible for ART are transferred to the ART programme until they graduate and transfer out to another ART facility. However, not all HIVinfected students opt to participate in this wellness programme and students often choose, rather, to receive treatment off campus by private clinicians. During 2015 this South African university had 102 students attending the on-campus wellness programme and only two students who tested positive during voluntary counselling and testing opted not to join this programme. However, according to the reported HIV prevalence on campuses in South Africa, ${ }^{4}$ the 102 students included in the HIV treatment programme in 2015 at this university may only represent a minority of the total number of HIV-infected students and private clinicians are likely to be responsible for the HIV management of an increasing number of students.

Nutrition-related complications such as weight loss in this population continue to remain challenging because, even in the context of ART, HIV disease progression seems to be strongly related to a compromised nutritional status. ${ }^{5}$ As a low/abnormal body mass index (BMI), especially at the time of ART initiation, has been associated with a higher mortality, ${ }^{4,6,7}$ it is extremely important to assess and monitor the nutritional status of newly diagnosed HIV-infected individuals. Apart from the nutritional status of HIV-infected students affecting their health, the quality of life and learning outcomes may also deteriorate in the presence of a compromised nutritional status. ${ }^{8}$ The failure to comply with medication regimens will increase the opportunistic infections, worsening the overall health status and outcome. It is well known that ART side effects may contribute to, amongst others, poor drug adherence in patients, ${ }^{10}$ and nutrition-related side effects such as decreased food intake, which may impact on the nutritional status, as well as cardiometabolic abnormalities 
and lipodystrophy. ${ }^{11-13}$ The latter, although not fatal, is associated with morphological effects that may impact on body image issues. Lipodystrophy seemingly occurs from the use of ART, particularly protease inhibitors but more recently the nucleoside analogue class has also been implicated. ${ }^{14}$ Switching to fixeddose combinations such as tenofovir (TDF)/emtricitabine (FTC) may result in decreased trunk fat and increased limb fat; however, as changes may only occur after one year, longitudinal studies are needed..$^{15}$ There is no consensus currently on the role that HIV infection itself, age, gender, genetics or other factors play on the development of lipodystrophy syndrome, but it is considered possible that HIV disease itself can play a role in this condition. The symptoms of lipodystrophy include central fat accumulation, peripheral fat depletion, and metabolic disturbances such as impaired glucose metabolism and dislipidaemia. ${ }^{16}$

Although research data on HIV risk behaviour in higher education institutions in South Africa are readily available, ${ }^{5}$ limited information can be found on the nutritional status and metabolic risk of students diagnosed with and living with HIV and how this may impact on their monitoring and management. The primary aim of the study was to describe the nutritional status including the anthropometry and energy intake, CD4 cell counts and metabolic risk among students managed as part of the ART and wellness programmes at a South African university. Furthermore, with this paper the authors attempt to highlight the complexity of HIV management in university students, given their unique situation where they spend approximately 36 to 44 weeks per year on campus without the support of their families and local family physician or health care professionals at clinics near home.

\section{Methods \\ Setting and design}

This descriptive, cross-sectional study was conducted among a convenience cohort of known HIV-infected, registered students, older than 18 years of age and managed as part of either the Campus Health Service wellness or ART programmes. Participants ( $n=63$ ) were admitted to the sample in 2013 after providing written, informed consent. Ethical approval was obtained from the Research Ethics Committee (Human) of the university (Ref No. H12-RTI-HIV-004).

\section{Measures}

Nutritional screening was performed by a trained, registered dietitian and included demographic, anthropometric, biochemical and clinical information as well as usual food intake. The dietitian measured the weight of participants to the nearest $0.1 \mathrm{~kg}$ using a Tanita BC $543^{\circledR}$ calibrated scale (Tanita Europe BV, Amsterdam, The Netherlands). Height measurements were obtained using a stadiometer to the nearest $0.1 \mathrm{~cm}$. All measurements were done according to standardised techniques ${ }^{9}$ with the participants wearing light clothing without shoes. The body mass index (BMI) is a simple index of weight-for-height that is commonly used to classify underweight, overweight and obesity in adults. It is defined as the weight in kilograms divided by the square of the height in metres $\left(\mathrm{kg} / \mathrm{m}^{2}\right)$. For the purpose of this study, a 'normal' BMI range was $18.5-24.9 \mathrm{~kg} / \mathrm{m}^{2}$. A BMI less than $18.5 \mathrm{~kg} / \mathrm{m}^{2}$ was considered to be 'underweight', a BMI of $25.0 \mathrm{~kg} / \mathrm{m}^{2}-29.9 \mathrm{~kg} / \mathrm{m}^{2}$ was considered 'overweight', and more than $30 \mathrm{~kg} / \mathrm{m}^{2}$ 'obese.. ${ }^{17}$ Waist circumference was measured with a tape measure around the abdomen at the narrowest point (ISAK guidelines) between the lowest rib and the iliac crest, and hip circumference as the maximum circumference over the buttocks. Both measurements were taken using an inelastic, flexible tape measure and were recorded to the nearest $0.1 \mathrm{~cm}$.
Disease risk was determined according to the NHLBI Obesity Education Initiative. ${ }^{17}$ Demographic, biochemical and clinical data were collected from the patient folder with permission of the participant. This included the most recent CD4 cell count that was obtained from the patient folder. The CD4 cell count was categorised according to a cut-off of 350 cells $/ \mathrm{mm}^{3}$. Clinical signs of lipodystrophy were assessed by a trained dietitian and were diagnosed if any of the following were present: lipoatrophy in arms, legs, buttocks or face; lipohypertrophy (central obesity, lipomas, buffalo hump) which developed since the participant started to use ART.

Statistical analysis was done with the Statistica ${ }^{\circledR}$ software package (version 10) (StatSoft, Tulsa, OK, USA). Frequencies and percentages were used to present categorical data and means and standard deviations for the numerical data. Subgroups in the BMI and CD4 cell count categories were compared using the Pearson chi-square test to test for statistical significant differences. Comparison of means was done using the MannWhitney $\mathrm{U}$ test to determine statistical significance $(p<0.05)$.

\section{Results}

The majority ( $n=50 ; 79 \%$ ) of participants were female (Table 1 ). Participants had a mean age of 23.98 years (SD $=5.38$ ) and $70 \%$ $(n=44)$ were between the age of 20 and 25 years. Some $56 \%$ ( $n$ = 33) of the cohort was diagnosed in the last 12 months before assessment. At the time of screening students in the cohort had a mean CD4 count of 411 (SD $=219.9$ ) cells $/ \mathrm{mm}^{3}$ with $55 \%$ of the sample having a CD4 cell count of more than 350 cells $/ \mathrm{mm}^{3}$.

Participants presented with a mean BMl of 28.05 (SD = 7.9) kg/ $\mathrm{m}^{2}$ and $30 \%(n=19)$ of them were obese. Only half of the participants $(n=31)$ were on ART. As HIV-infected students were only initiated on ART after CD4 cell counts dropped below 350

Table 1: Demographic data, clinical and anthropometric nutritional status $(n=63)$

\begin{tabular}{|c|c|c|c|}
\hline Variable & & $n$ & $\%$ \\
\hline \multirow{2}{*}{ Gender } & Male & 13 & 21 \\
\hline & Female & 50 & 79 \\
\hline \multirow{3}{*}{ Age group } & $<20$ years & 3 & 5 \\
\hline & $20-25$ years & 44 & 70 \\
\hline & $>25$ years & 19 & 30 \\
\hline \multirow{4}{*}{ Time period since diagnosis } & $0-2$ months & 17 & 29 \\
\hline & 3-11 months & 16 & 27 \\
\hline & $12-23$ months & 12 & 20 \\
\hline & $>24$ months & 12 & 20 \\
\hline \multirow[t]{4}{*}{$\begin{array}{l}\text { Weight change in last } \\
6 \text { months (\% of normal weight) }\end{array}$} & More than $5 \%$ weight loss & 4 & 8 \\
\hline & Less than $5 \%$ weight loss & 16 & 33 \\
\hline & $\begin{array}{l}\text { Less than } 5 \% \text { weight gain or } \\
\text { stable }\end{array}$ & 24 & 49 \\
\hline & More than $5 \%$ weight gain & 5 & 10 \\
\hline \multirow{4}{*}{ BMI category $\left(\mathrm{kg} / \mathrm{m}^{2}\right)$} & $<18.5$ (underweight) & 2 & 3 \\
\hline & 18.5 to 24.9 (normal weight) & 29 & 46 \\
\hline & 25-29.9 (overweight) & 13 & 21 \\
\hline & $30+$ (obese) & 19 & 30 \\
\hline \multirow{3}{*}{ CD4 cell count (cell/ $/ \mathrm{mm}^{3}$ ) } & $<200$ & 9 & 16 \\
\hline & $200-349$ & 17 & 29 \\
\hline & $350+$ & 32 & 55 \\
\hline
\end{tabular}




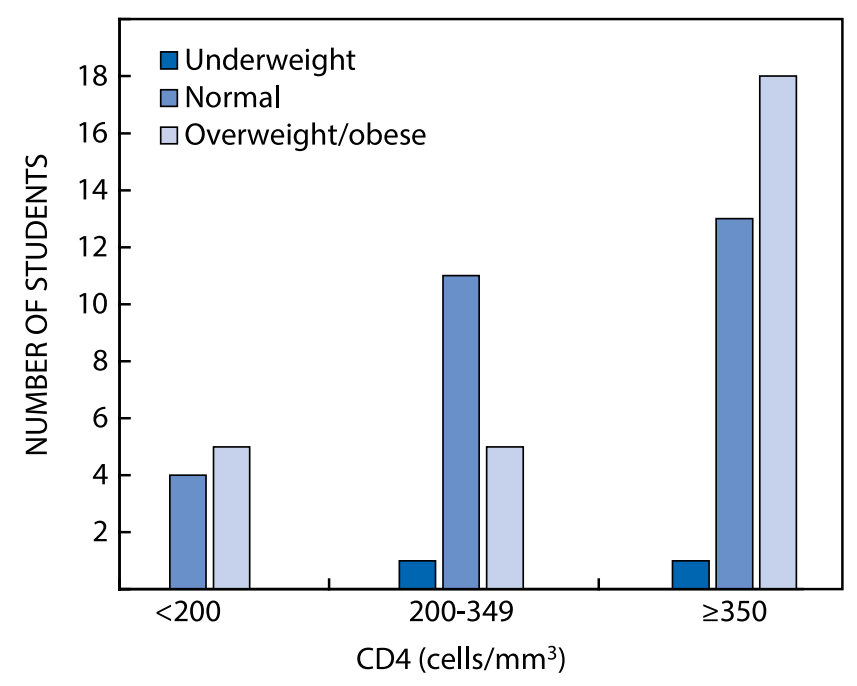

Figure 1: Frequency distribution of CD4 count in relation to BMI group.

cells $/ \mathrm{mm}^{3}$, participants on ART had a significantly lower $(p<$ 0.005) mean CD4 cell count ( 323 cell $/ \mathrm{mm}^{3}$ ) compared with those not on ART (494 cell $\left./ \mathrm{mm}^{3}\right)$. This finding was of large practical significance with a Cohen's d value of 0.84 . A higher BMI ( $>25 \mathrm{~kg} /$ $\left.\mathrm{m}^{2}\right)$, and thus being overweight, was significantly $(p<0.05$; $V=0.32$ ) associated with higher CD4 cell counts of $>350$ cells/ $\mathrm{mm}^{3}$ (see Figure 1). Only $8 \%(n=4)$ of the sample reported involuntary weight loss of more than $5 \%$ in the previous 3 months, indicating an increased nutritional risk. However, despite being on ART, three of the four participants had CD4 cell counts less than 250 cells $/ \mathrm{mm}^{3}$. Only one of the participants had a compromised nutritional intake, consuming less than $70 \%$ of the Dietary Recommended Intake, and had a BMI of $16.4 \mathrm{~kg} / \mathrm{m}^{2}$.

With regard to disease risk, $19 \%(n=12)$ of students were identified as being at an increased risk, $5 \%(n=3)$ at high risk, $17 \%(n=11)$ at very high risk and $10 \%(n=6)$ at extremely high risk based on their waist circumference and BMI (Figure 2).

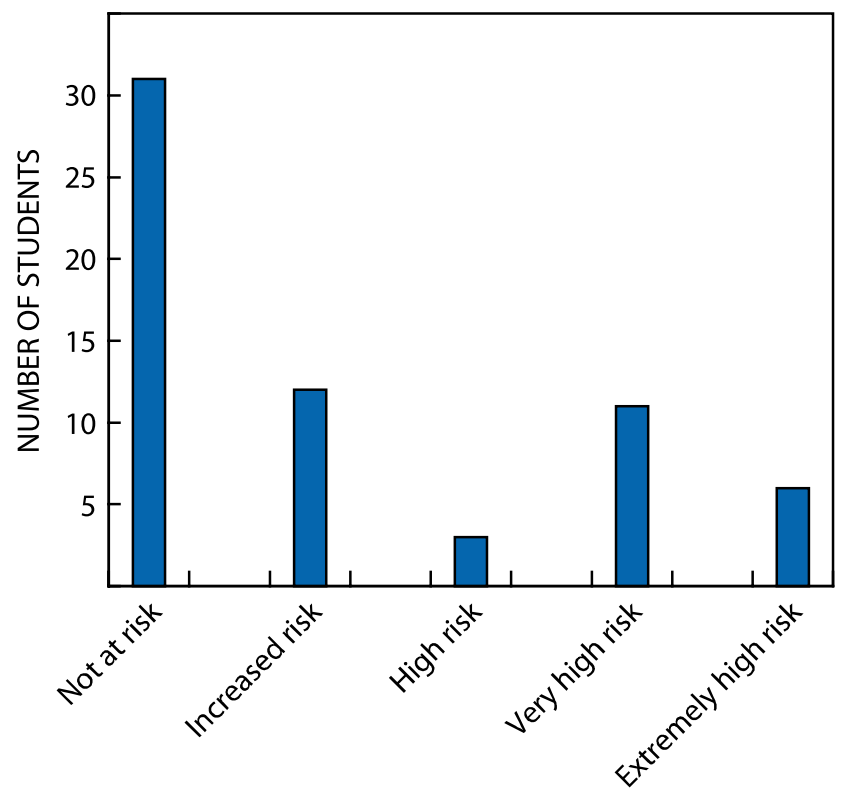

Disease risk according to waist circumference and BMI

Figure 2: Frequency distribution of students according to disease risk as measured by the NHLBI Obesity Education Initiative. ${ }^{17}$
The mean estimated energy intake was $29.6(\mathrm{SD}=11.6) \mathrm{kcal} / \mathrm{kg}$. The 'obese' group consumed a mean energy intake of $24 \mathrm{kcal} / \mathrm{kg}$ bodyweight versus $27 \mathrm{kcal} / \mathrm{kg}$ bodyweight in the 'overweight' group and $34 \mathrm{kcal} / \mathrm{kg}$ bodyweight in the normal weight group. Although this reflected a significant $(p=0.008)$ difference between the BMI groups, with the obese group consuming significantly less energy per kg bodyweight than the other groups, it should be acknowledged that the overweight group could have been underreporting their dietary intake, which is a common occurrence within overweight and obese individuals. ${ }^{18}$

\section{Discussion}

Clinically the HIV-infected young adult often presents as physically stunted with delayed puberty and adrenarche, dependent on when they contracted HIV. In addition, the adolescent and the young adult with HIV have to deal with numerous psychological stressors such as acceptance of HIV status, the need for lifelong ART, future health status and in total the fact that they are infected and affected for life. ${ }^{19}$ Any stunting and growth retardation has a huge psychological impact on adolescents, for whom body image is important, and a weakened immune system makes them vulnerable to recurrent infections and illnesses. ${ }^{19}$ The immune status of HIV-infected students in this study seem to be affected by a BMI $<25 \mathrm{~kg} / \mathrm{m}^{2}$ and being overweight or obese were associated with higher CD4 cell counts irrespective of being on ART or not. As the entry criteria for the ART programme changed from a CD4 cell count of 350 cells $/ \mathrm{mm}^{3}$ prior to this study to 500 cells $/ \mathrm{mm}^{3}$ after completion of this study, it is possible that the lower CD4 cell count associated with the group on ART is the result of the previous more stringent entry criteria to qualify for ART. However, despite the 'protective' effect that overweight had on the immune status, on the downside almost half of this sample was at risk of cardiometabolic abnormalities such as dyslipidaemia and impaired glucose metabolism based on their BMI and waist circumference. ${ }^{11,17}$ Careful individualised approaches towards dietary and lifestyle interventions are therefore necessary to minimise deterioration of immune status and the development of diseases..$^{20}$

Although a significant difference between the BMI groups was found regarding energy intake, with the obese group consuming significantly less energy per $\mathrm{kg}$ bodyweight than the other groups, it should be acknowledged that the overweight group could have been underreporting their dietary intake, which is a common occurrence within overweight and obese individuals. ${ }^{18}$ Another explanation might be the body composition changes, decreased insulin sensitivity and dyslipidaemia associated with HIV infection. ${ }^{11}$ In practice it implies that dietitians and clinicians should be careful with aggressive restriction of energy and macronutrients in overweight and obese HIV-infected youth.

Such individualised approaches have to be balanced with an understanding of what it means to work with this emotionally vulnerable age group. It is hard to predict how they will respond to their HIV disease status. For instance many adolescents will avoid accessing healthcare services for fear of disclosure. Equally, denial due to fear of the HIV infection lends itself to nonconformity to treatment. ${ }^{21}$ While ARTs have been identified as having several advantages, particularly greater longevity of people living with HIV/AIDS, their use is also associated with harmful changes, particularly physical and metabolic changes. ${ }^{22}$ Obesity, dietary imbalances and sedentary lifestyles further aggravate these metabolic disturbances. In fact, obesity has been identified as a key risk factor for metabolic complications such as coronary heart diseases and type 2 diabetes mellitus when 
correlated with physical inactivity among people living with HIV/ AIDS and using ARTs. Therefore adolescents and young adults need to be informed that the side effects of ARTs can be prevented and/or treated by engaging in regular physical activity. ${ }^{23}$

Furthermore weight problems are common among people who are HIV-infected, particularly women. Interestingly, in this sample of HIV-infected students, the majority of participants were overweight/obese prior to the study and a minority reported weight loss in the three months prior to the study. Overweight persons with HIV infection are more at risk of developing metabolic and body composition abnormalities such as lipodystrophy, and this observation was confirmed by the results found among this sample of HIV-infected students. Obtaining a balance between a healthy weight and high dietary quality among HIV-infected youth may be a challenge because diet quality is often poor among adolescents and young adults who have HIV infection. This is particularly evident when considering documented lifestyle habits of university students in which physical inactivity is highlighted as being common. ${ }^{24,25}$ Accordingly nutritional education in order to improve diet quality and physical activity should be advised so that overall quality of life is improved. ${ }^{26-29}$ This is especially important because despite the fact that exercise has been found to be beneficial and is encouraged for people living with HIV, only $25 \%$ of HIV-positive people engage in sufficient levels of healthbenefiting physical activity. ${ }^{23}$

Challenges regarding HIV for adolescents in general include: medication-related side effects, misinformation, distrust of the medical establishment, fear and lack of belief in the medication, particularly when they experience lipodystrophy, unstructured and chaotic lifestyles and refusal to take medication and adhere to principles of treatment for HIV due to rebellion, drug resistance issues. ${ }^{19}$ Physical inactivity among students as found in previous South African studies adds a further burden health wise by increasing the development of non-communicable diseases. ${ }^{23}$ Such inactivity is aggravated by the side effects of ARTs, a heavy academic workload and perceived lack of time on the part of students. ${ }^{30}$ The benefits of physical activities/exercise in people living with HIV/AIDS while being treated with ARTs include improvement of their quality of life and well-being, strength, and their increasing functional work capacity. Other benefits comprise psychological effects and self-efficacy. In addition, physical fitness and the ability to perform activities of daily living, an improvement of the body's ability to fight infection and slower progression of HIV to AIDS have been noted. ${ }^{23}$

A challenge experienced by healthcare providers is to balance wellness and ARV treatment, especially for adolescents and young adults, particularly sufficient adherence counselling..$^{10}$ Ongoing professional counselling support is particularly required on campus for students taking ARTs. The second challenge is to ensure that the ART patients remain compliant during long winter and summer vacations. Although they are provided with sufficient medication it appears to be difficult for them to comply when they are at home. It is postulated that this issue could be due to disclosure issues, lifestyle of the youth and psychosocial constraints. The third critical challenge occurs when students on ARTs have failed their final examinations and do not return to university the following year. This results in them nothaving medication and having notransfer-out documentation to ensure continuation of their care. The campus health service professional nurses and counsellors attempt to locate such students and ensure treatment continuation but loss to follow- up of many students/patients remains a reality. This specific population of patients accessing ARTs at campus health clinics therefore poses specific challenges that require unique interventions. Private clinicians need to acknowledge that these issues may even be more pronounced in students receiving care off campus. For instance one of the reasons that students seek health care off campus might include the fear of stigmatisation; therefore they choose the anonymity of a private practitioner. However, in the absence of formal wellness or ART programmes, students treated by general practitioners could be even less likely to adhere to ART, especially in the context of ART side effects, signs of lipodystrophy and a possible lack of counselling. Counselling, which assists with adherence to medication, is offered free of charge by campus health clinics but is unlikely to be offered in a time-challenged and cost-conscious private practice setting. The small sample size was a limitation; however, half of the total number of patients treated on campus participated in the study. The authors also acknowledge that the experiences of HIV-infected students who receive treatment off campus can provide further valuable information to improve care and support of this particular group.

\section{Conclusion and recommendation}

It is imperative to manage the young adult holistically within the context of his/her own economic, cultural, psychological and family environment. ${ }^{19}$ ART is a reality for all HIV-positive patients despite the associated potentially serious adverse effects, such as metabolic and morphologic changes. ${ }^{23}$ These effects can be prevented and/or treated by engaging in regular physical activity, having adequate nutritional intake, regular monitoring and evaluation of side effects, BMI, and preferably being combined with optimal care and support. Further studies should be conducted to compare the findings of students who are attending the campus health clinic with those who are not attending the campus health clinic, to try and determine whether the outcomes of their disease status differ when using outside clinics.

\section{References}

1. Shisana O, Rehle T, Simbayi LC, et al. South African national HIV prevalence, Incidence and behaviour survey. Cape Town: HSRC Press; 2014.

2. Johnson LF. Access to antiretroviral treatment in South Africa, 20042011. South Afr J HIV Med. 2012;13. [cited 2016 June 3]. Available from: http://www.sajhivmed.org.za/index.php/hivmed/article/ view/156/261

3. April, MD, Wood, R, Berkowitz, BK, et al. The survival benefits of antiretroviral therapy in South Africa. J Infect Dis. 2013. [cited 2016 June 3]. Available from: http://jid.oxfordjournals.org/ content/209/4/491.full.pdf+html

4. Heaids. HIV prevalence and related factors-higher education sector study, South Africa, 2008-2009. Pretoria: Author; 2010.

5. Liu E, Spiegelman D, Semu H, et al. Nutritional status and mortality among HIV-infected patients receiving antiretroviral therapy in Tanzania. J Infect Dis. 2011;204(2):282-90. http://dx.doi.org/10.1093/ infdis/jir246

6. Mangili A, Murman DH, Zampini AM, et al. Nutrition and HIV infection: review of weight loss and wasting in the era of highly active antiretroviral therapy from the nutrition for healthy living cohort. Clinic Infect Dis. 2006;42:836-42. http://dx.doi.org/10.1086/500398

7. Masiira B, Baisley K, Mayanja BN, et al. Mortality and its predictors among antiretroviral therapy naïve HIV-infected individuals with CD4 cell count $\geq 350$ cells $/ \mathrm{mm}^{3}$ compared to the general population: data from a population-based prospective cohort in Uganda. Glob Health Action. 2014;7. [cited 2016 June 3]. Available from: http://www.ncbi. nlm.nih.gov/pmc/articles/PMC3895200/

8. Munro N, Quayle M, Simpson H, et al. Hunger for knowledge: Food insecurity among students at the University of KwaZulu-Natal Perspect Educ. 2013;31(4):168-79. 
9. Lee RD, Nieman DC. Nutritional Assessment. 6th ed. New York: Mc-Graw Hill; 2013.

10. Reda AA, Biadgilign S. Determinants of adherence to antiretroviral therapy among HIV-infected patients in Africa. AIDS Res Treat. 2012, [cited 2016 May 28]. Available from: http://www.hindawi.com/ journals/art/2012/574656/abs/

11. Stanley TL, Grinspoon SK. Body composition and metabolic changes in HIV-infected patients. J Infect Dis. 2012;205:S383-90. http://dx.doi.org/10.1093/infdis/jis205

12. Van Wijk JPH, Cabezas MC. Hypertriglyceridemia, metabolic syndrome, and cardiovascular disease in HIV-infected patients: effects of antiretroviral therapy and adipose tissue distribution. Int J Vasc Med. 2012. [cited 2016 May 28]. Available from: http://www. hindawi.com/journals/ijvm/2012/201027/abs/

13. White, R. Symposium 8: drugs and nutrition. Drugs and nutrition: how side effects can influence nutritional intake: Conference on Malnutrition matters; 2009 Oct 13-14; Cardiff: Cardiff International Arena; 2010. p. 558-64.

14. Sued O, Figueroa MI, Cahn P. Clinical challenges in HIV/AIDS: Hints for advancing prevention and patient management strategies. Adv Drug Deliv Rev. 2016. [cited 2016 June 3]. Available from: http://www. sciencedirect.com/science/article/pii/S0169409X16301260

15. Curran A, Martinez E, Podzamczer D, et al. Changes in body composition and mitochondrial DNA in HIV-1-infected patients switching to fixed-dose abacavir/lamivudine or tenofovir/ emtricitabine: a substudy of the BICOMBO Trial. Antiviral Therapy. 2012;17:711-8. doi:10.3851/IMP2081.

16. George JA, Venter WD, Van Deventer HE, et al. A longitudinal study of the changes in body fat and metabolic parameters in a South African population of HIV-positive patients receiving an antiretroviral therapeutic regimen containing stavudine. AIDS Res Hum Retrov. 2009;25(8):771-81. http://dx.doi.org/10.1089/aid.2008.0308

17. National Institutes of Health National Heart, Lung and Blood Institute (NHLBI) Obesity Initiative. The practical guide identification, evaluation, and treatment of overweight and obesity in adults. 2000. [cited 2016 May 28]. Available from: http://www.nhlbi.nih.gov/files/ docs/guidelines/prctgd_c.pdf

18. Mendez MA, Popkin BM, Buckland G, et al. Alternative methods of accounting for underreporting and overreporting when measuring dietary intake-obesity relations. Am J Epidemiol. 2010;173(4):448-58.

19. Naswa S, Marfatia YS. Adolescent HIV/AIDS: Issues and Challenges. Indian J Sex Transm Dis AIDS. 2010;31(1):1-10.
20. Tiozzo E, Konefal J, Adwan S, et al. A cross-sectional assessment of metabolic syndrome in HIV-infected people of low socioeconomic status receiving antiretroviral therapy, Diabetol Metab Syndr. 2015;7:15. [cited 2016 September 4]. Available from: http:// dmsjournal.biomedcentral.com/articles/10.1186/s13098-015-0008-5 http://dx.doi.org/10.1186/s13098-015-0008-5

21. Collins E, Wagner C, Walmsley S. Psychosocial impact of the lipodystrophy syndrome in HIV infection. AIDS Read. 2010;10(9): 546-50.

22. Hurley E, Coutsoudis A, Giddy J, et al.Weight evolution and perceptions of adults living with HIV following initiation of antiretroviral therapy in a South African urban setting. SAMJ. 2011;101(9):645-50.

23. Frantz JM, Murenzi A. The physical activity levels among people living with human immunodeficiency virus/acquired immunodeficiency syndrome receiving high active antiretroviral therapy in Rwanda. J Soc Aspects HIV/AIDS. 2014;10(3-4):113-8.

24. Pengpid S, Peltzer K. Physical inactivity and associated factors among university students in South Africa. Afr J Phys Health Educ Recr Dance. 2013;19(1):143-53.

25. Bloemhoff HJ. Gender- and race-related physical activity levels of South African university students. Afr J Phys Health Educ Recr Dance. 2010;16(4):25-35.

26. Kruzich LA, Marquis GS, Wilson CM, et al. HIV-infected US youth are at high risk of obesity and poor diet quality: A challenge for improving short- and long-term health outcomes. J Acad Nutr Diet. 2004;104(10):1554-60.

27. Gresse A, Steenkamp L, Pietersen J. Eating, drinking and physical activity in Faculty of Health Science students compared to other students at a South African university. South Afr J Clin Nutr. 2015;28(4):164-9.

28. Van den Berg V, Okeyo A, Dannhauser A, et al. Body weight, eating practices and nutritional knowledge amongst university nursing students, Eastern Cape, South Africa, Afr J Prim Health Care Fam Med. 2012;4(1), [cited 2016 May 28]. Available from: http://www.phcfm. org/index.php/phcfm/article/view/323

29. Van den Berg L, Raubenheimer J. Food insecurity among students at the University of the Free State, South Africa. S Afr J Clinic Nutr 2015;28(4):160-9. http://dx.doi.org/10.1080/16070658.2015.117345 56

30. Dhurup M, Garnett A. Self-reported constraints to physical activity participation among university students. Afr J Phys Health Educ Recr Dance. 2011;(September Supplement):86-103. 